\title{
Dissolved $\mathrm{CO}_{2}$ in natural waters: development of an automated monitoring system and first application to Stromboli volcano (Italy)
}

\author{
Salvatore Inguaggiato ${ }^{1,}$, Lorenzo Calderone $^{1}$, Claudio Inguaggiato $^{2}$, Sabina Morici $^{1}$, Fabio Vita $^{1}$ \\ ${ }^{1}$ Istituto Nazionale di Geofisica e Vulcanologia, sezione di Palermo, Palermo, Italy \\ ${ }^{2}$ Università degli Studi di Palermo, Facoltà di Scienze Matematiche, Fisiche e Naturali, Palermo, Italy
}

\author{
Article history \\ Received March 11, 2011; accepted May 25, 2011. \\ Subject classification: \\ Gas-water interaction, Dissolved $\mathrm{CO}_{2}$, Fluid geochemistry, Geochemical monitoring.
}

\section{ABSTRACT}

The study of geochemical parameters applied to natural systems has provided improved knowledge of geochemical mechanisms of gas/rock dissolution in natural waters that are linked to gas-water and/or waterrock interaction processes. Here we present the results of our studies focused on the development of an automated monitoring system for measuring the amount of dissolved $\mathrm{CO}_{2}$ in natural waters. The system is based on the principle of a dynamic equilibrium between water and the air as the host gas. The $P_{\mathrm{CO}_{2}}$ measurements were carried out every four hours, and the equilibration time was around 20 minutes. Moreover, application to the thermal aquifer of Stromboli volcano during the 2009-2010 period is shown and analyzed. The data highlight a clear correlation between the changes in the $P_{\mathrm{CO} 2}$ in the thermal aquifer and the changes in volcanic activity.

\section{Introduction}

Over the last 15 years, fluid geochemistry as applied to active volcanic areas has markedly improved our knowledge of the physico-chemical relationships between magmatic and crustal fluids. This improvement has allowed the formulation of geochemical models that are more and more refined, and that are suitable for an understanding of the geochemical variations linked to changes in volcanic activity [Bonfanti et al. 1996a, Bonfanti et al. 1996b, Capasso et. al 2000, Inguaggiato et al. 2000, Inguaggiato et al. 2005, De Gregorio et al. 2007, Inguaggiato et al. 2010, Inguaggiato et al. 2011]. Within this framework, many studies have addressed the monitoring of geochemical parameters that can help in the collection of information relating to the levels of volcanic activity. Geochemical surveillance of an active volcano is aimed at recognizing possible signals that are related to changes in the volcanic activity. Indeed, as a consequence of magma depressurization inside the "plumbing system" and/or of the refilling of the magma reservoirs from new batches of gas-rich melt, the volatiles dissolved in the magma are progressively released according to their relative solubilities in the basaltic melt. As they approach the surface, the fluids discharged during magma degassing can interact with shallow aquifers and/or can be released along the main volcano-tectonic structures.

High-frequency acquisition of geochemical parameters is a target of many studies that are aimed at improving our knowledge of a volcanic system and at highlighting shortterm variations in volcanic activity. The first step is to select the "sensitive" parameters to be monitored, and to select an adequate frequency for the data acquisition. The next step is to identify the "sensitive" sites where the monitoring instrumentation needs to be installed.

Continuous monitoring of geochemical parameters often needs complex equipment. Furthermore, on active volcanoes, the best monitoring sites are often located in areas that are difficult to reach and are sometimes dangerous, like active crater areas. For these reasons, in many cases, it is better to search for suitable sites for monitoring systems in peripheral areas of a volcanic system.

The aim of this study was both to develop an automated and remote monitoring system for measurement of $\mathrm{P}_{\mathrm{CO} 2}$ in equilibrium with the natural ground-waters, and to test such in the field by measuring cold and thermal waters located in active volcanic areas (i.e., Etna and Stromboli volcanoes). Finally, considering that Stromboli volcano is characterized by high frequency of strombolian activity, we carry out a long-term test of the prototype of this automated system in a Stromboli thermal aquifer, to investigate possible relationships between $\mathrm{P}_{\mathrm{CO} 2}$ and summit volcanic activity.

\section{Geochemical approach to monitoring volcanic fluids}

Shallow magma located beneath active volcanoes releases volatiles both during eruptive activity (active degassing) and during inter-eruptive periods (passive degassing). Fumarolic fluids in active volcanic areas arise directly from the magma, and in order of abundance, their 
composition is characterized mainly by $\mathrm{H}_{2} \mathrm{O}, \mathrm{CO}_{2}, \mathrm{SO}_{2}, \mathrm{H}_{2} \mathrm{~S}$, $\mathrm{HF}$ and $\mathrm{HCl}$ (condensable gases), and by some noncondensable gases $\left(\mathrm{He}, \mathrm{H}_{2}, \mathrm{~N}_{2}, \mathrm{CO}\right)$.

However, during their migration towards the surface, steam and gas can condense and/or dissolve in shallow fluids, such as ground-water, giving origin to hydrothermal aquifers. In terms of mass balance, the relative contributions of each degassing process are mainly dependent on the type of volcanism and on the intensity of the volcanic activity.

Considering their high mobility relative to magma, volatiles can provide useful indications about the state of the volcanic activity. There are always gas emissions in a volcanic system during paroxysmal activity, and these are often the only visible manifestations during the inter-eruptive periods (solphataric activity).

Gas-water interaction processes modify the pristine physico-chemical characteristics of shallow fluids, thus providing useful information regarding both the origin of the fluids and the degree of this interaction at depth. In many cases, significant geochemical changes have been observed in the thermal states of some shallow groundwaters located near active volcanic systems [Capasso and Inguaggiato 1998, Capasso et al. 2000, Inguaggiato et al. 2000, Inguaggiato et al. 2005, Inguaggiato et al. 2010]. This suggests that the relevant input of magmatic gas into the shallow aquifer occurs before changes in the level of volcanic activity; i.e., before eruptions and explosions, and before increases in the number of fumarolic vents and the total volatiles flux [Inguaggiato et al. 2011, Capasso et al. 2005, Carapezza et. al 2004].
The thermal waters, therefore, look promising as targets for geochemical monitoring of active volcanoes. They might represent probable connections with the deep-gas sources, such as a volcano magma chamber and/or deep-seated geothermal reservoirs.

To provide better insight into the importance of hydrothermal systems associated with active volcanoes, the geochemical behaviors of several chemical parameters of naturally discharged fluids have been reported. Within an overall geochemical model, these parameters can provide important information regarding possible changes in volcanic activity. Among these, there are:

- $p \mathrm{H}$ and $\mathrm{P}_{\mathrm{CO} 2}: \mathrm{pH}$ measurements provide indications about the presence of acid fluids that reach the surface, and that can interact with ground-waters and change their normal physico-chemical characteristics. In particular, acid fluids can be represented by acid condensates that are rich in $\mathrm{HF}, \mathrm{HCl}$ and sulfur species, or by pure gas phases, like $\mathrm{CO}_{2}$, which once dissolved in an aquifer, results in a decrease in $\mathrm{pH}$. On the basis of the chemical balance between carbon species in solution and $\mathrm{pH}$, it is possible to estimate the partial pressure of the $\mathrm{CO}_{2}$ in equilibrium with the aquifer $\left(\mathrm{P}_{\mathrm{CO} 2}\right)$. Therefore, both $\mathrm{pH}$ and $\mathrm{P}_{\mathrm{CO} 2}$ provide good indications of the degree of the gas-water interaction processes [Inguaggiato et. al. 2000, Carapezza et. al. 2004, Inguaggiato et. al. 2005, Inguaggiato et al. 2011].

- Temperature: Measurements of the well/spring temperatures, coupled with their water discharge, can provide information about the energy transfer from both the hot and the deep fluids towards the surface. This energy

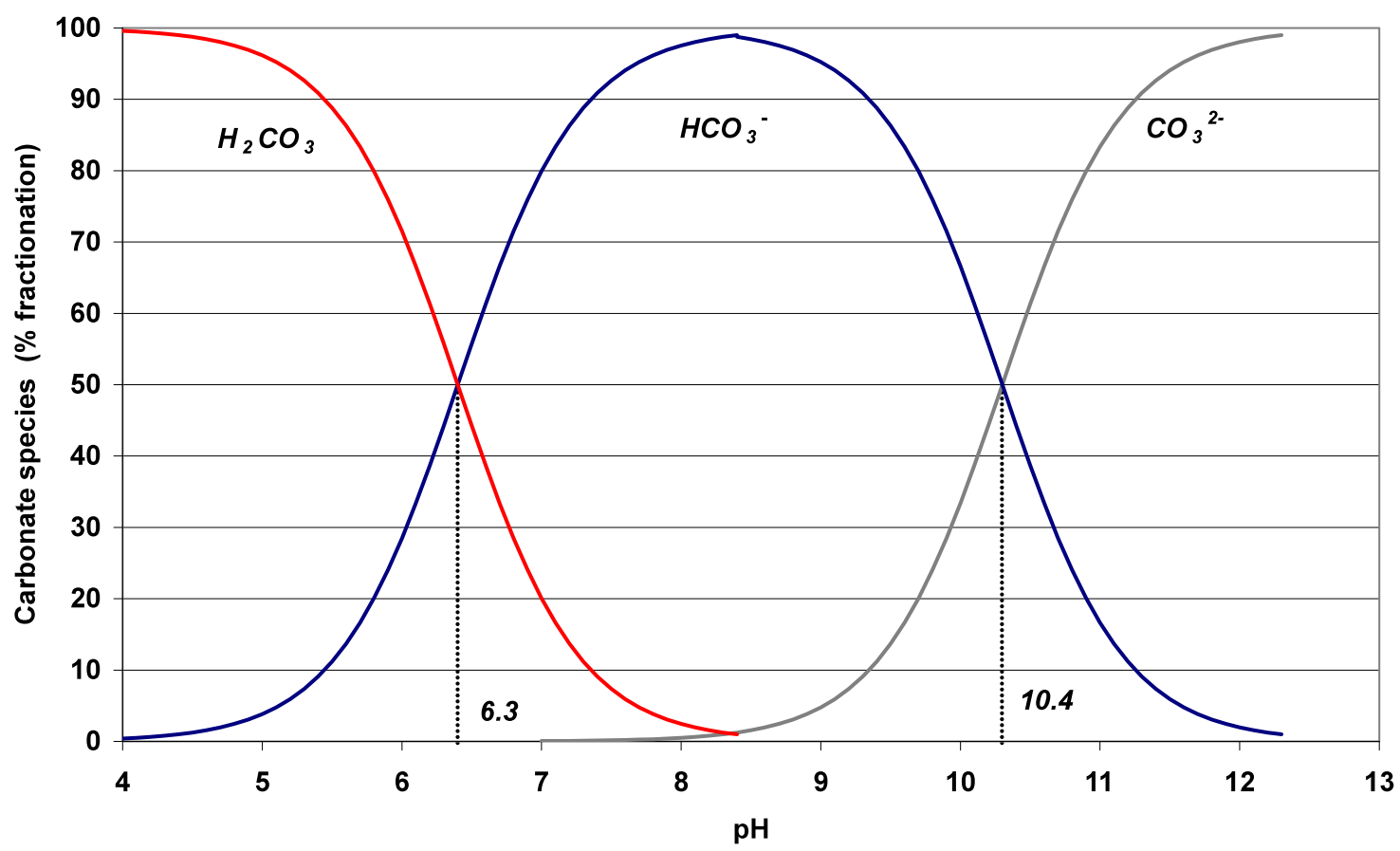

Figure 1. Stability fields of the carbon species (as indicated) in pure water on the basis of the water $\mathrm{pH}$. The $\mathrm{pHs}$ of 6.3 and 10.3 (vertical dotted lines) indicate the inflection points, where the ratios of the carbon species are equal to 1.0 (for the $\mathrm{H}_{2} \mathrm{CO}_{3}-\mathrm{HCO}_{3}$ and $\mathrm{HCO}_{3}-\mathrm{CO}_{3}$ pairs). 


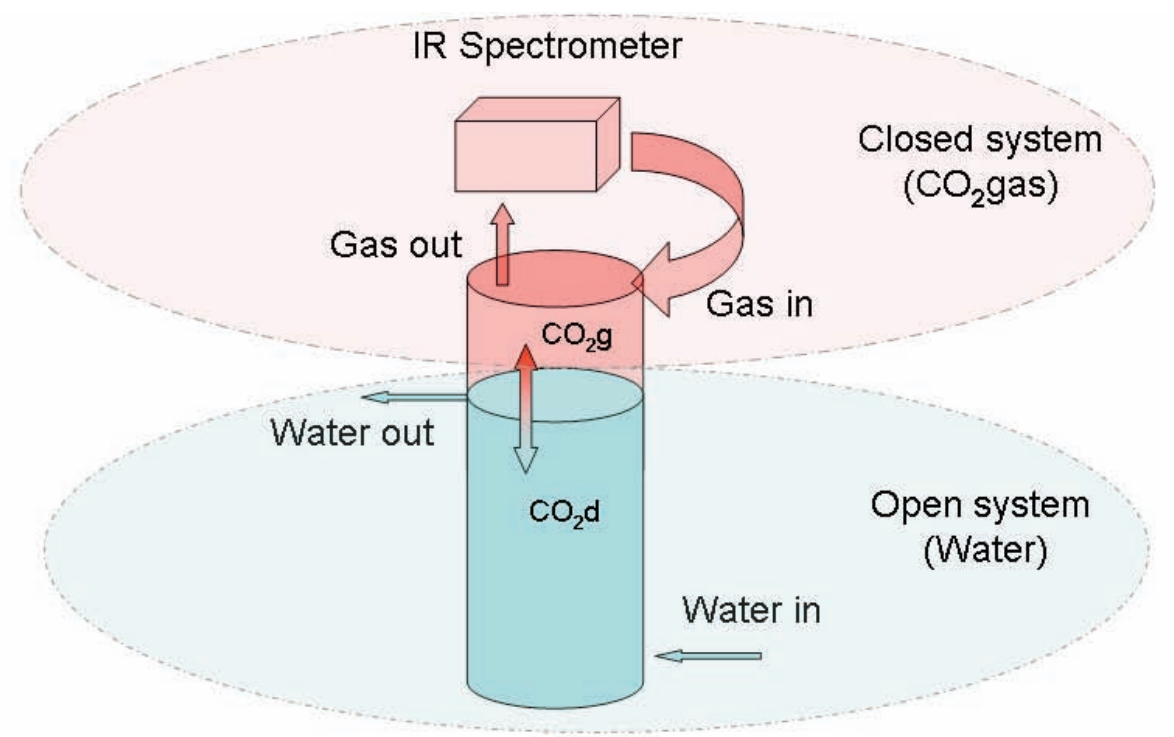

Figure 2. Schematic representation of the automated monitoring system for measuring $\mathrm{P}_{\mathrm{CO} 2}$. There are two main circuits: an open water system, driven by a peristaltic pump that pumps the water from the well, and a closed gas system that is driven by a small gas pump that circulates the $\mathrm{CO}_{2}$ between the head-space of the equilibration chamber and the IR spectrometer.

transfer can result in significant variations in the average temperatures of shallow aquifers, with an increase in the water temperature that can overlap, and exceed, the normal seasonal oscillations of an aquifer [Bonfanti et al. 1996a, Bonfanti et al. 1996b].

- Conductivity: Measurements of the electrical conductivity of natural waters can provide information about their salinity. Changes in salinity can indicate changes in the end-member mixing (meteoric and sea waters) and/or the input of deep and saline fluids.

- Phreatic level: Close to volcanic areas, the groundwater levels can be influenced by interactions between volcanic and shallow fluids. Indeed, under particular conditions, the gas accumulation in the soils caused by high gas efflux along active tectonic structures can produce temporary decreases in both the permeability and the flow of the ground-water, thus resulting in increases in the local phreatic level [Capasso et al. 1999].

Dissolution of $\mathrm{CO}_{2}$ in natural waters: theoretical principles

The $\mathrm{CO}_{2}$ released from a magma batch during magma degassing processes produces a series of physico-chemical reactions as it interacts with shallow fluids during its rise towards the surface. During its dissolution in water, $\mathrm{CO}_{2}$ reacts with $\mathrm{H}_{2} \mathrm{O}$, forming carbonic acid

$$
\mathrm{CO}_{2(\mathrm{~g})}+\mathrm{H}_{2} \mathrm{O} \leftrightarrow \mathrm{H}_{2} \mathrm{CO}_{3}
$$

Carbonic acid is a weak acid that is ionized in natural waters through the following reactions:

$$
\begin{gathered}
\mathrm{H}_{2} \mathrm{CO}_{3} \leftrightarrow \mathrm{H}^{+}+\mathrm{HCO}_{3}^{-} \\
\mathrm{HCO}_{3}^{-} \leftrightarrow \mathrm{H}^{+}+\mathrm{CO}_{3}^{2-}
\end{gathered}
$$

The equilibria of these reactions are ruled by the constants K1 and K2, with values of $10^{-6.4}$ in Equation (2) and $10^{-10.3}$ in Equation (3), in pure water at $25^{\circ} \mathrm{C}$. Consequently, the ratio among the carbon species of $\mathrm{H}_{2} \mathrm{CO}_{3}, \mathrm{HCO}_{3}{ }^{-}$and $\mathrm{CO}_{3}{ }^{2-}$ in solution is strongly dependent on the $\mathrm{pH}$, and through simple calculations it is possible to obtain the theoretical percentages of the single species as functions of $\mathrm{pH}$ (Figure 1).

Dissolution of $\mathrm{CO}_{2}$ in water produces a decrease in $\mathrm{pH}$. Therefore, measurement of $\mathrm{pH}$ can provide indications on the amounts of dissolved $\mathrm{CO}_{2}$ in water, and allow calculation of the $\mathrm{P}_{\mathrm{CO} 2}$ in equilibrium with an aquifer:

$$
\begin{gathered}
\mathrm{CO}_{2(\mathrm{~g})}+\mathrm{H}_{2} \mathrm{O} \leftrightarrow \mathrm{HCO}_{3}^{-} \\
\operatorname{logK}=\log \left(\mathrm{HCO}_{3}^{-}\right)+\log \left(\mathrm{H}^{+}\right)-\log \left(\mathrm{CO}_{2}\right) \\
\mathrm{pH}=\log \left(\mathrm{HCO}_{3}^{-}\right) /\left(\mathrm{CO}_{2}\right)+\mathrm{pK}
\end{gathered}
$$

Unfortunately, continuous measurements of $\mathrm{pH}$ are affected by many technical problems that do not allow the use of $\mathrm{pH}$ for long periods of monitoring (weeks to months). This is mainly when the natural waters have high temperatures and/or high salinities. For this reason, we focused our efforts on providing automated equipment to continuously measure the content of the dissolved $\mathrm{CO}_{2}$ in these natural waters. The system is based on the dynamic equilibrium between gases dissolved in a liquid phase and a host-gas phase (in this case, air). Henry's Law describes this physico-chemical principle: at chemical equilibrium and at constant temperature, a known volume of liquid in contact with a given gas dissolves a quantity of gas that is proportional to the gas pressure on the liquid (Henry's Law). This is expressed by the following relation: 


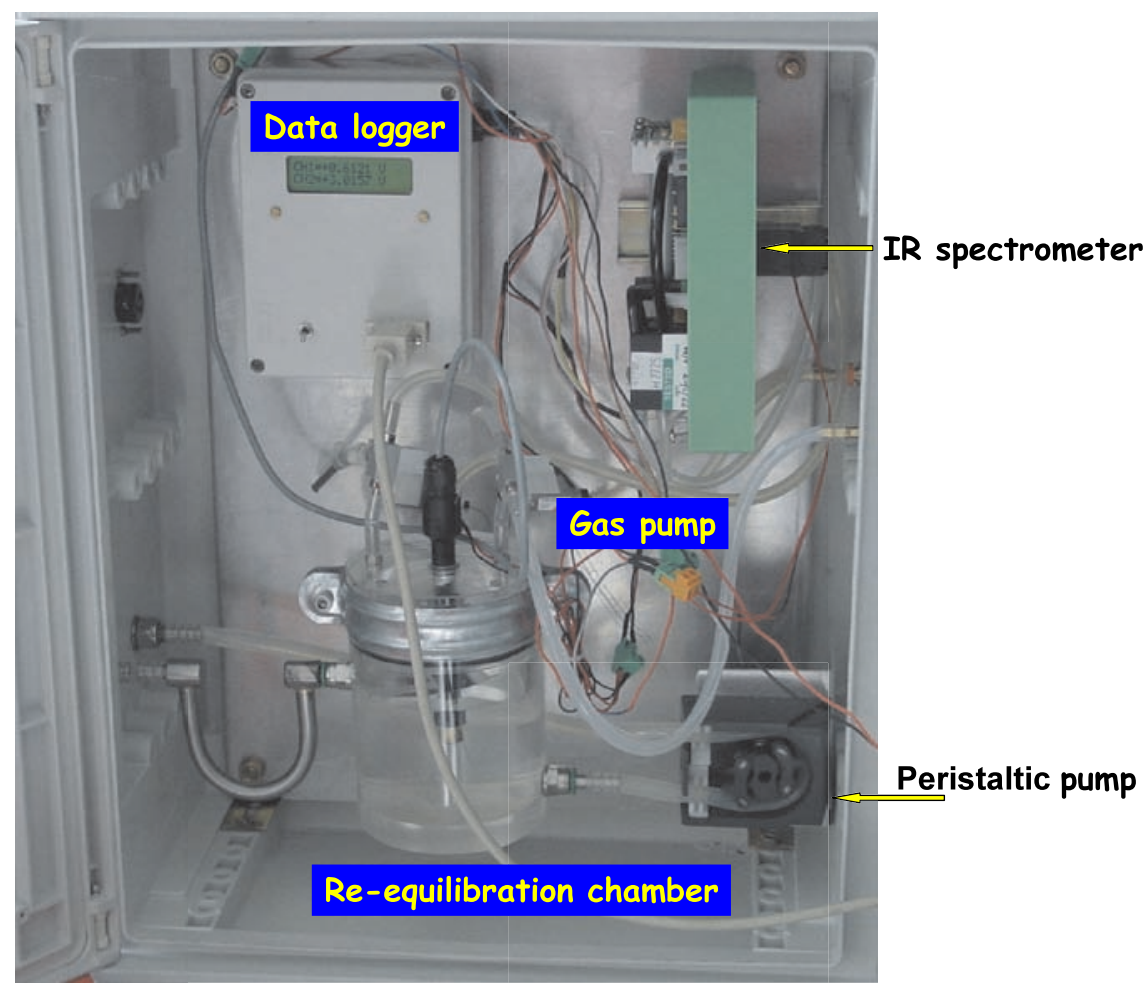

Figure 3. Photograph of the prototype of the continuous monitoring station for measuring dissolved $\mathrm{CO}_{2}$ in natural waters.

$$
\mathrm{K}_{\mathrm{H}}=\mathrm{Pi} / \mathrm{Xi}
$$

where $\mathrm{Pi}$ is the partial pressure of the $\mathrm{i}^{\text {th }}$ gas in the vapor phase (in atmospheres) and $\mathrm{Xi}$ is its molar fraction in the liquid phase. Henry's constant $\left(\mathrm{K}_{\mathrm{H}}\right)$ does not depend on the total gas pressure, and it varies according to both temperature and salinity [Capasso and Inguaggiato 1998].

\section{Technical features}

\section{of the automated system for monitoring $\mathbf{P}_{\mathrm{CO} 2}$}

The automated system that was designed during the present study is represented by two main circuits: an opensystem circuit, where water flows through, and a closed-system circuit, where gases exsolved from and reequilibrated with the water circulate and are analyzed using an infrared (IR) spectrometer (Figure 2). A peristaltic pump sends the water to a Plexiglas re-equilibration chamber that has a total volume of about $500 \mathrm{~mL}$, with the proportions of $450 \mathrm{~mL}$ and $50 \mathrm{~mL}$ between the water and the air, respectively. The water level inside the chamber is kept constant by a U-shaped system that discharges any excess water (Figure 3). The water that is circulating inside the open system starts re-equilibrating its dissolved $\mathrm{CO}_{2}$ with the host gas (the $50 \mathrm{~mL}$ of air inside the chamber), according to Henry's Law. The system reaches equilibrium in about 20 min. At the same time, the gas pump allows the circulation of the gas inside the closed-circuit system that is between the re-equilibration chamber and the IR spectrometer. The amount of $\mathrm{CO}_{2}$ in the circulating gas phase is measured by the IR spectrometer, and it increases with time until it reaches the value corresponding to that at complete equilibrium with $\mathrm{CO}_{2}$ in water: $\mathrm{P}_{\mathrm{CO} \text { (gas) }} \leftrightarrow \mathrm{P}_{\mathrm{CO} \text { (water) }}$ (Figure 4). The concentration of $\mathrm{CO}_{2}$ is automatically measured in the air inside the chamber both before and after each reequilibration cycle. The values of $\mathrm{CO}_{2}$ reached at the end of the equilibration time (about $20 \mathrm{~min}$ ) represent the partial pressures of the $\mathrm{CO}_{2}$ in the natural system being studied at the measured water temperature (Figure 4). The data acquired are recorded by a data logger, and they are then sent by GSM to the Geochemical Acquisition Centre of the INGV in Palermo.

The automated system to measure the dissolved $\mathrm{CO}_{2}$ comprises the following main items:

- Re-equilibration chamber (developed at INGV, Palermo);

- Peristaltic pump (Rietschle Thomas, Germany);

- Data logger (developed at INGV, Palermo);

- IR spectrometer (Edinburgh Sensors, UK);

- Gas pump (KNF, Germany);

- Phreatic level sensor (STS, Switzerland);

- Temperature sensor inside the chamber (Analogical

Devices, USA);

- Temperature probe inside the well (Analogical Devices, USA);

- Conductivity sensor (B\&C, Italy).

\section{Laboratory tests and calibration system}

Calibration tests of the IR spectrometer were carried out in the laboratory using standard gas mixtures with different concentrations of $\mathrm{CO}_{2}$ (range, $0 \%$ to $98 \%$ vol. $\mathrm{CO}_{2}$ ). 


\section{Scheme cycle measurements}

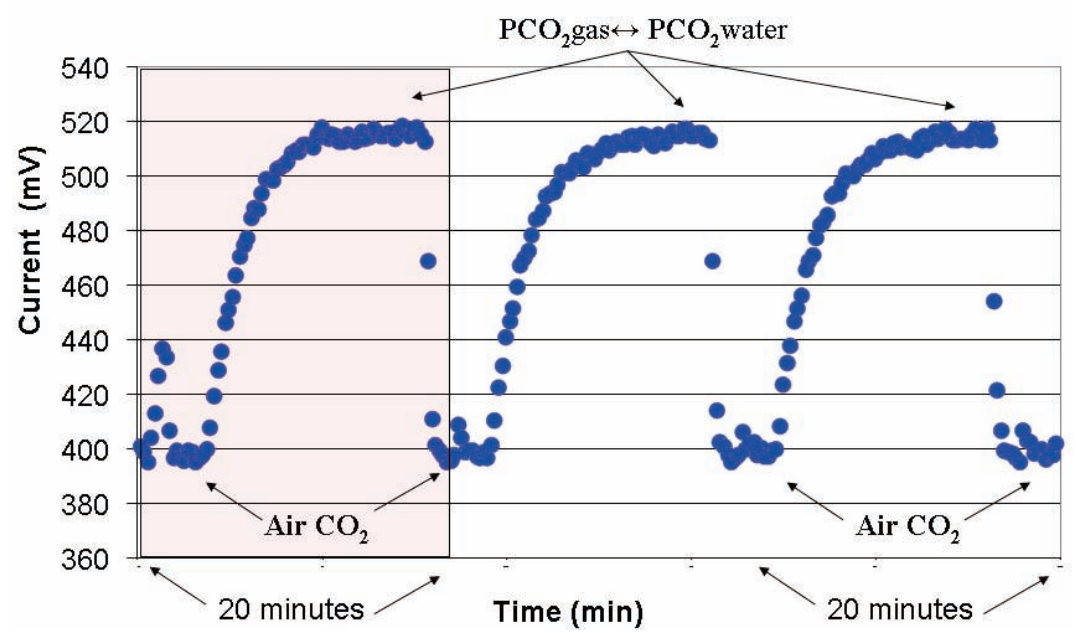

Figure 4. Example of measurement cycles of the dissolved $\mathrm{CO}_{2}$ concentration $(\mathrm{mV})$. These cycles reach equilibrium in $15-20 \mathrm{~min}$. The air $\mathrm{CO}_{2}$ content is measured both before and after every cycle. Six measurement cycles were performed each day (one every $4 \mathrm{~h}$ ).

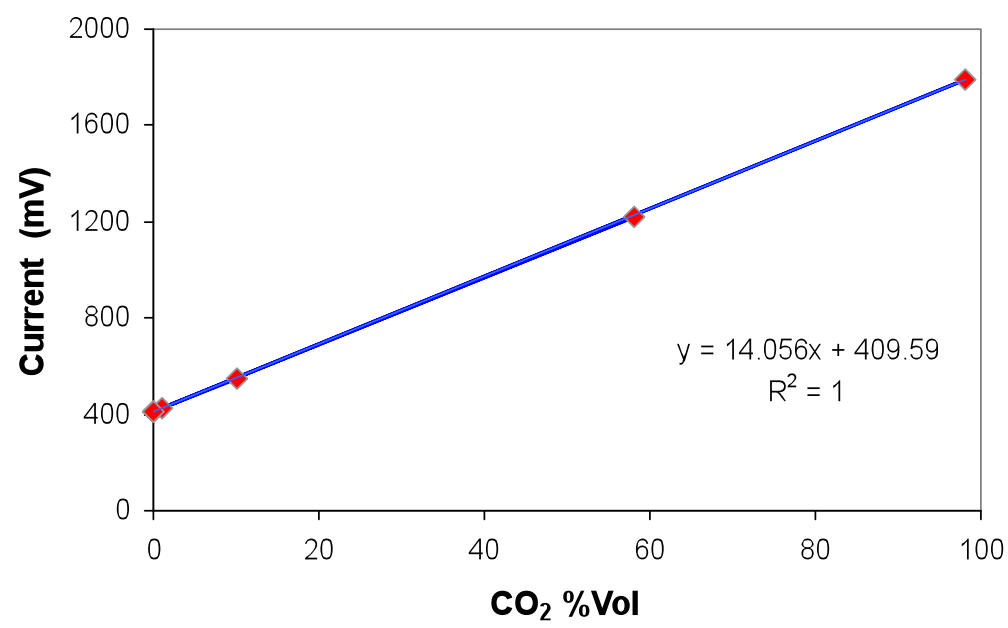

Figure 5. Calibration of the IR spectrometer used in the automated monitoring system for $\mathrm{P}_{\mathrm{CO}}$, performed with standards of mixed gases with known $\mathrm{CO}_{2}$ concentrations in air (from $0.034 \%$ to $100 \%$ vol. $\mathrm{CO}_{2}$ ).

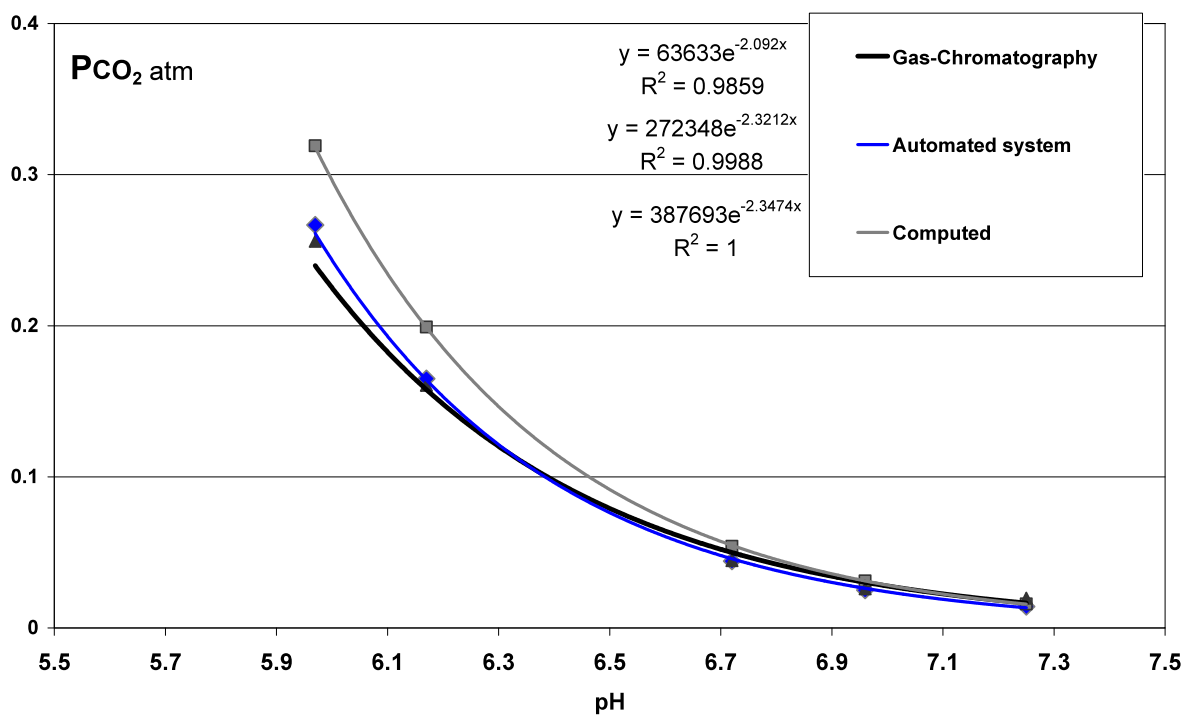

Figure 6. Comparisons between $\mathrm{CO}_{2}$ partial pressures and pHs obtained with the laboratory tests. The three curves represent the best fits of the $\mathrm{P}_{\mathrm{CO} 2}$ values both measured (using the automated system and gas chromatography analysis) and computed on the basis of the $\mathrm{pH}$ and the $\mathrm{HCO}_{3} \mathrm{content}$ The different values of $\mathrm{P}_{\mathrm{CO} 2}$ and $\mathrm{pH}$ were obtained by continually bubbling pure $\mathrm{CO}_{2}$ through natural water. The data highlight the good correlation between the different ways used for estimating the $\mathrm{P}_{\mathrm{CO} 2}$ and the reliability of the automated prototype system. 

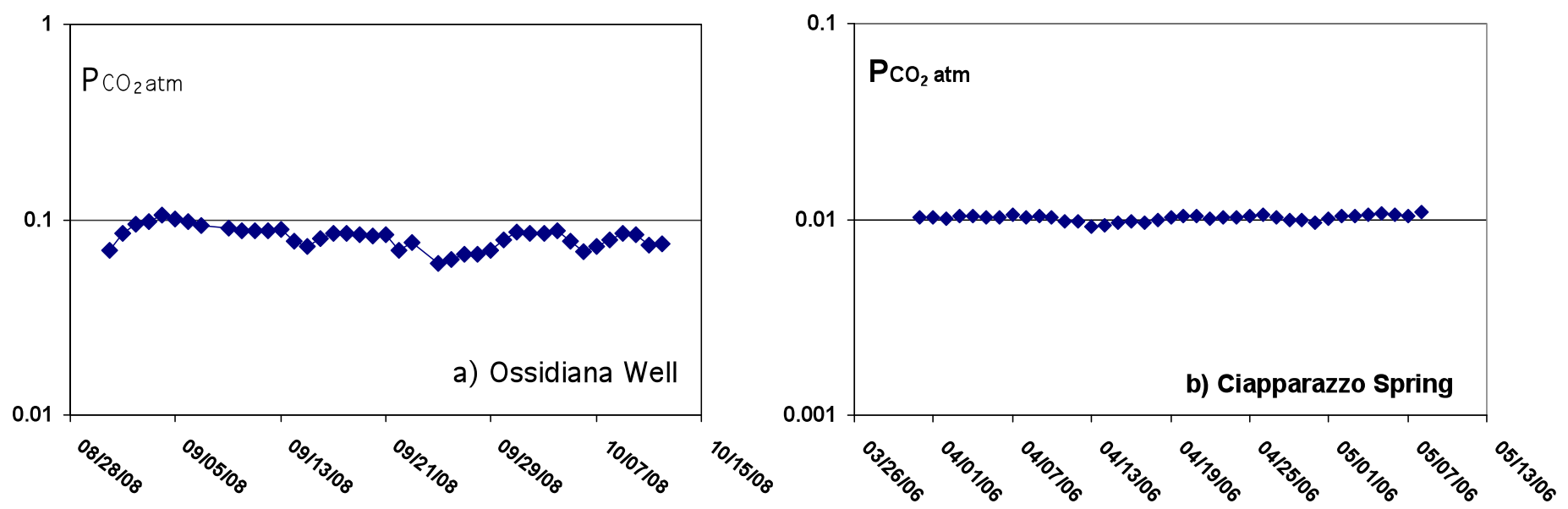

Figure 7. Field measurements of $\mathrm{P}_{\mathrm{CO} 2}$ for the Ossidiana well (a) and the Ciapparazzo spring (b). Ossidiana well (temperature, $40{ }^{\circ} \mathrm{C}$; salinity, $30 \mathrm{mS} / \mathrm{cm}$ ) is located in the village of Stromboli (Stromboli Island), and Ciapparazzo spring is located on the flank of Mt. Etna (temperature, $13^{\circ} \mathrm{C}$; salinity, $700 \mu \mathrm{S} / \mathrm{cm}$ )

The good linear response obtained with the IR spectrometer is shown in Figure 5.

Operation system tests were performed using six aqueous solutions at different $\mathrm{pHs}$ (range, 5.90 to 7.25 ) and different amounts of dissolved $\mathrm{CO}_{2}$. (range, 0.01 to $0.3 \mathrm{~atm}$ $\mathrm{P}_{\mathrm{CO} 2}$ ). To perform this experiment, a $20 \mathrm{~L}$ tank of water was used. The aqueous solutions at different $\mathrm{pHs}$ were prepared by bubbling pure $\mathrm{CO}_{2}$ through the water. The $\mathrm{pHs}$ and the bicarbonate contents of the solutions were measured during the experiments, to estimate the corresponding $\mathrm{P}_{\mathrm{CO} 2}$ values. Samples of the dissolved gases $\left(\mathrm{CO}_{2}\right)$ were also collected at different $\mathrm{pHs}$ for gas-chromatography analysis. Figure 6 shows the $\mathrm{P}_{\mathrm{CO} 2}$ values both as computed and as measured with the different methods (gas chromatography and automated IR spectrometer) plotted against the corresponding $\mathrm{pHs}$. The plot in Figure 6 highlights the good correlation between the $\mathrm{P}_{\mathrm{CO} 2}$ analyzed using gas chromatography and the $\mathrm{P}_{\mathrm{CO} 2}$ analyzed using this new automated IR spectrometer system. Moreover, the computed $\mathrm{P}_{\mathrm{CO} 2}$ values estimated on the basis of the $\mathrm{pHs}$ and the $\mathrm{HCO}_{3}{ }^{-}$contents, also provide good data that are very close to the measured values. Only in the range of $\mathrm{pH}$ close to 6.4 (Figure 1, inflection point) are there small differences with the measured values. This is probably due to the strong logarithmic relationship between $\mathrm{pH}$ and $\mathrm{P}_{\mathrm{CO} 2}$ at this value, where small differences in $\mathrm{pH}$ can result in very large differences in computed $\mathrm{P}_{\mathrm{CO} 2}$.

\section{Short-term experimental test on natural systems}

After verifying the good operation of the prototype system in the laboratory, we tested it in the field by measuring natural waters with different physico-chemical characteristics. Therefore, we installed two experimental monitoring systems, one in a cold spring (Ciapparazzo, NW flank of Mt. Etna volcano), and the other in a thermal well (Ossidiana, Stromboli Island). Ciapparazzo spring is located inside a drainage gallery, with a drainage flow of about 700 $\mathrm{L} / \mathrm{s}$. This spring is characterized by low temperature and low salinity $\left(13{ }^{\circ} \mathrm{C}\right.$ and $700 \mu \mathrm{S} / \mathrm{cm}$, respectively). Ossidiana well is located on the north-east side of Stromboli Island (an active volcano that is characterized by persistent strombolian activity), and it is characterized by temperatures of around $40{ }^{\circ} \mathrm{C}$ and high salinity (about $30 \mathrm{mS} / \mathrm{cm}$ ). The equipment installed in these different natural waters worked successfully, and Figure 7 shows the results of the daily averages of $\mathrm{P}_{\mathrm{CO} 2}$ values acquired over the 2-3 months of observation.

\section{Long-term variations in dissolved $\mathrm{CO}_{2}$}

On the basis of the promising results obtained from these first two prototype stations, the geochemical application of this methodology was carried out on Stromboli Island, by installing a revised and improved second version of the prototype monitoring system in a thermal well that had been drilled for scientific purposes (Saibbo Well, on the north-east side of Stromboli Island).

We analyzed the complete $\mathrm{P}_{\mathrm{CO} 2}$ dataset acquired at the Saibbo well station during 2009-2010, which represented the first continuous dataset of dissolved $\mathrm{CO}_{2}$ recorded in a well located in an active volcanic system. To improve our knowledge of the behavior of the $\mathrm{P}_{\mathrm{CO} 2}$, and to link its variations to the different degassing regimes, we processed these $\mathrm{P}_{\mathrm{CO} 2}$ data using a cumulated probability graph [Sinclair 1974]. This graph is shown in Figure 8, where the $P_{C O 2}$ is plotted against the cumulated probability for the entire dataset (2009-2010). On the basis of the thresholds identified, we divided these data into three different subsets $(\mathrm{B}, \mathrm{H}$ and P). Group B includes values below 0.12 atm, which represents about $60 \%$ of the total acquired dataset, and it refers to a low degree of gas-water interaction. Group $\mathrm{H}$ includes about $40 \%$ of the total acquired dataset, with higher values that range between $0.12 \mathrm{~atm}$ and $0.32 \mathrm{~atm}$, and which are interpreted as a high degree of gas/water interaction. The third group $(\mathrm{P})$ includes very few data (only $1 \%$ of the total acquired dataset), with values up to $0.6 \mathrm{~atm}$.

The histogram of the relative frequencies within the full 


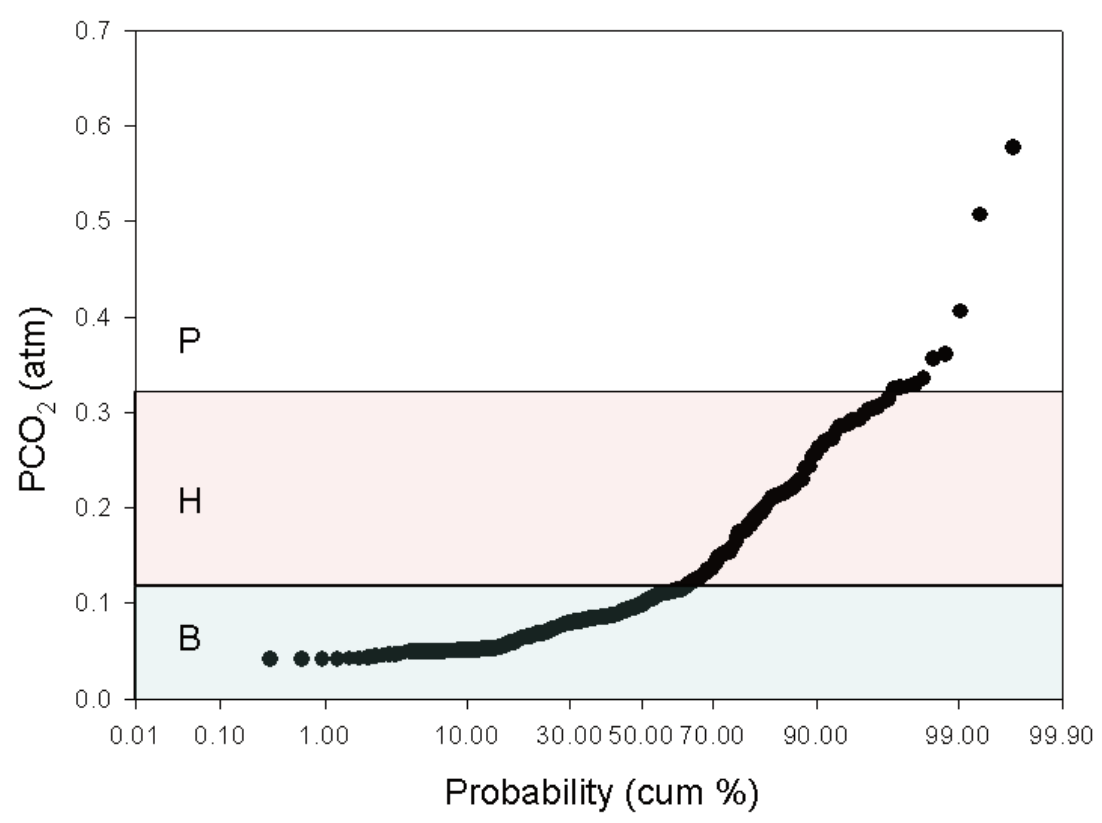

Figure 8. $\mathrm{P}_{\mathrm{CO} 2}$ values measured for the Saibbo well plotted against cumulated probability of $\mathrm{P}_{\mathrm{CO} 2}$ values for the entire dataset (2009-2010). Boxes with letters $\mathrm{P}, \mathrm{H}$ and $\mathrm{B}$ indicate the three subsets defined in this analysis (see main text).

acquired dataset (Figure 9) shows an asymmetric unimodal distribution of $\mathrm{P}_{\mathrm{CO} 2}$, which is centered at around $0.1 \mathrm{~atm}$, with a residual "tail" of values up to $0.6 \mathrm{~atm}$. The average value of $\mathrm{P}_{\mathrm{CO} 2}(0.1 \mathrm{~atm})$ computed from the data in group $\mathrm{B}$ represents the background value during "low" gas-water interactions in the Saibbo well. The right residual tail values (group P) range from $0.4 \mathrm{~atm}$ to $0.6 \mathrm{~atm}$ and warrant separate discussion and elaboration. Indeed, even though group P includes only about $1 \%$ of the $\mathrm{P}_{\mathrm{CO} 2}$ dataset - which is insufficient for statistical elaboration - it represents the highest $\mathrm{P}_{\mathrm{CO} 2}$ values and it would identify the transient variations due to the very high degree of gas-water interaction.

The daily averages of $\mathrm{P}_{\mathrm{CO} 2}$ normalized at standard temperature and pressure (STP) conditions are plotted against time in Figure 10, together with the main explosive events that occurred at the summit craters of Stromboli volcano. Two important behaviors can be seen: an increase in $\mathrm{P}_{\mathrm{CO} 2}$ with time from January 2009 to May 2010, with values starting from $0.07 \mathrm{~atm}$ that reach $0.60 \mathrm{~atm}$. This behavior suggests a slow and persistent increase in the dissolved gases in the thermal aquifer; moreover, a series of transient increases in $\mathrm{P}_{\mathrm{CO} 2}$ were recorded at different times during the 2009-2010 period, thus suggesting sharp and significant increases in the gas-water interactions that are likely to be due to new input of volatiles from deep magmatic sources.

It can also be seen that many of these sharp increases in $\mathrm{P}_{\mathrm{CO} 2}$ were followed by increases in the summit volcanic activity. In particular, a slow increase in $\mathrm{P}_{\mathrm{CO} 2}$ was recorded from January 2009 (0.07 atm) to April 25, 2009 (0.32 atm). The $\mathrm{P}_{\mathrm{CO} 2}$ then quickly returned to background values $(0.10$ $\mathrm{atm}$ ), and one week later a paroxysmal event (major explosion) occurred at the summit crater of Stromboli volcano. The $\mathrm{P}_{\mathrm{CO} 2}$ of Saibbo well then remained almost constant until early October 2009, when a new series of sharp increases in $\mathrm{P}_{\mathrm{CO} 2}$ were recorded, until November 1, 2009. Then, two major explosions occurred, on November 8 and 24, 2009. A further sharp increase in $\mathrm{P}_{\mathrm{CO} 2}$ with a significant peak (up to $0.32 \mathrm{~atm}$ ) occurred on December 14, 2009 , followed by two strong explosions on January 4 and 10, 2010. The first semester of 2010 was characterized by a general increase in $\mathrm{P}_{\mathrm{CO} 2}$ driven by two large increments that occurred on April 14, 2010 (0.35 atm), and May 27, 2010 (0.61 $\mathrm{atm}$ ), and that culminated in a $\mathrm{P}_{\mathrm{CO} 2}$ of $0.61 \mathrm{~atm}$. After this large increase in $\mathrm{P}_{\mathrm{CO} 2}$, the explosive activity of Stromboli volcano increased significantly, leading to a major explosive event that occurred on June 30, 2010.

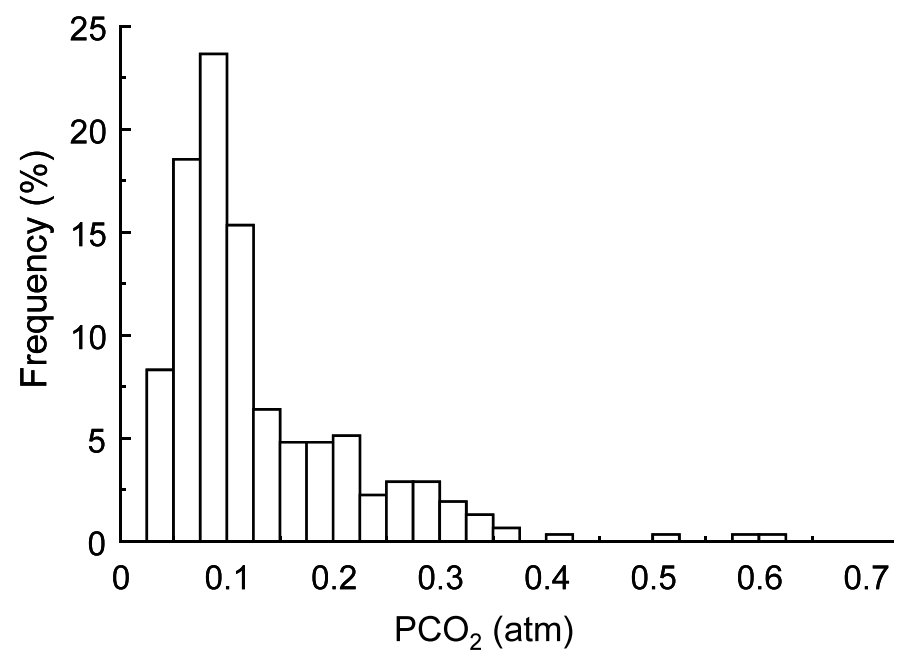

Figure 9. Histogram showing the distribution frequency (\%) of the $\mathrm{P}_{\mathrm{CO} 2}$ values from Saibbo well. The plot shows unimodal distribution of the $\mathrm{P}_{\mathrm{CO} 2}$ values centered around $0.1 \mathrm{~atm}$, with residual 'tail' values up to $0.6 \mathrm{~atm}$. 


\section{Saibbo Well}

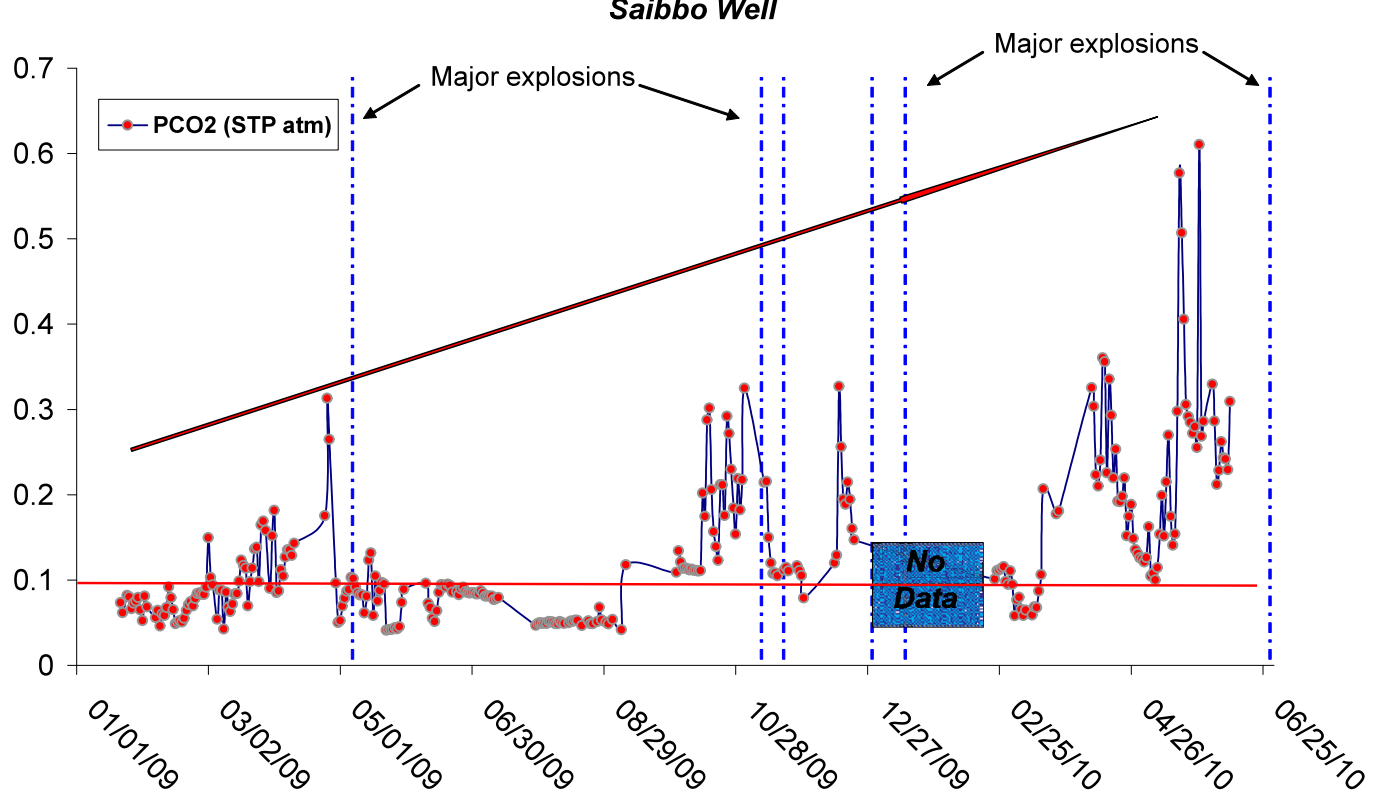

Figure 10. Long-term variations of $\mathrm{P}_{\mathrm{CO} 2}(\mathrm{STP}$, atm) for Saibbo well, as acquired from continuous recordings. Vertical blue dashed lines, major explosions from the summit craters of Stromboli volcano from January 2009 to June 2010.

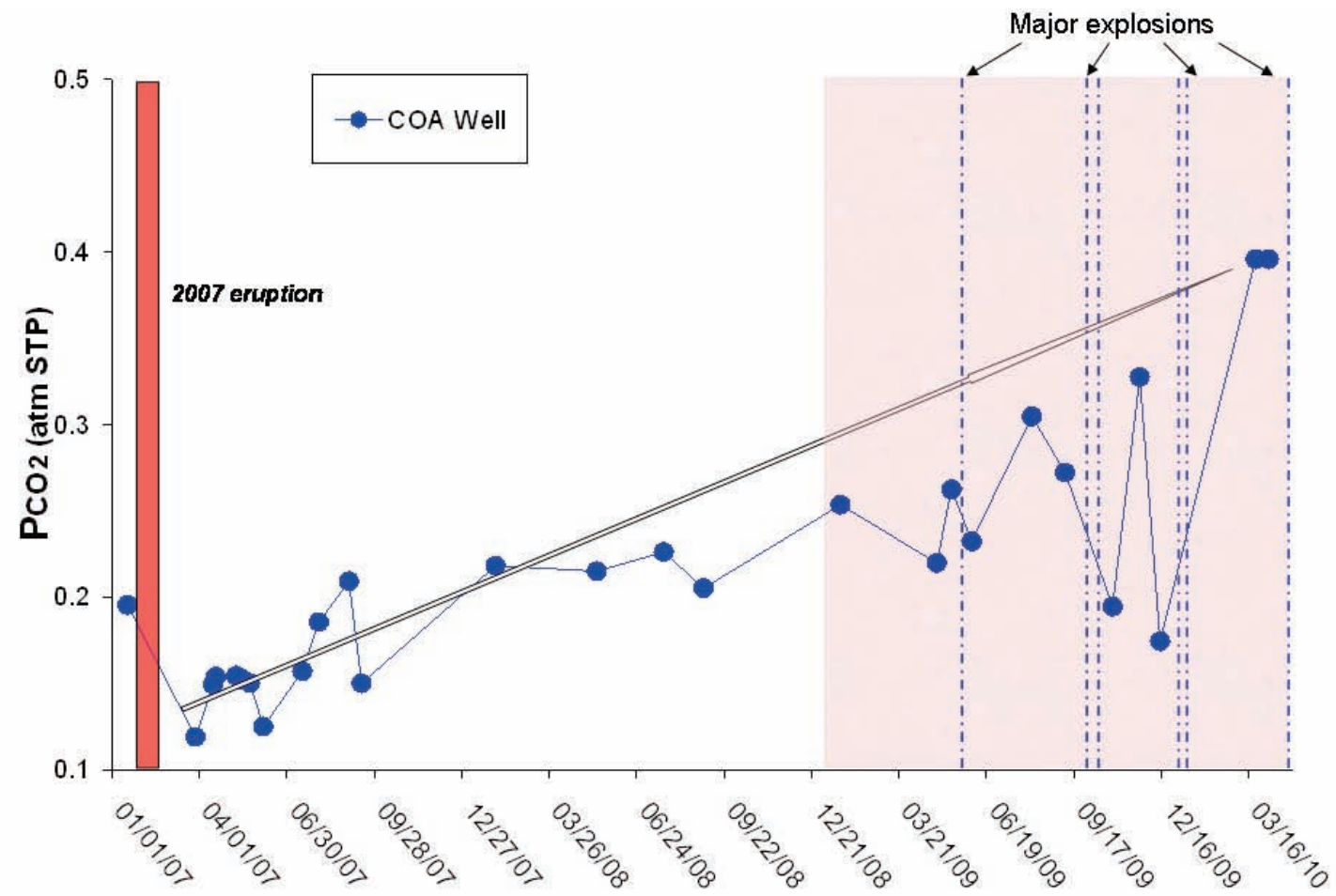

Figure 11. Long-term variations in the $\mathrm{P}_{\mathrm{CO} 2}(\mathrm{STP}$, atm) for the COA well, as acquired with low-frequency sampling. This graph highlights the positive trend of $\mathrm{P}_{\mathrm{CO} 2}$ with time (arrow) from the end of the last major eruption of Stromboli volcano (April 2007) to the present. The 2007 eruption (red column) and the major explosions that occurred in the period from January 2009 to June 2010 (red transparent area, vertical blue dashed lines) are shown.

\section{Discussion and conclusions}

High-frequency acquisition of geochemical parameters is one of the main targets of geochemical volcano monitoring. The acquisition of these parameters at different sites and for different types of shallow fluid manifestations represents a good way to obtain a complete picture of a geochemical model of a volcanic system under study.

$\mathrm{CO}_{2}$ is one of the main species that needs to be monitored in a volcanic system. The prototype of the monitoring station described in this study provides us with the opportunity to significantly improve the data acquisition frequency of $\mathrm{P}_{\mathrm{CO} 2}$, and the possibility for the better modeling of hydrothermal systems in active volcanoes. Moreover, the improved amounts of data allow investigations into the relationships among hydrothermal systems, peripheral soil degassing, and summit volcanic activity. 

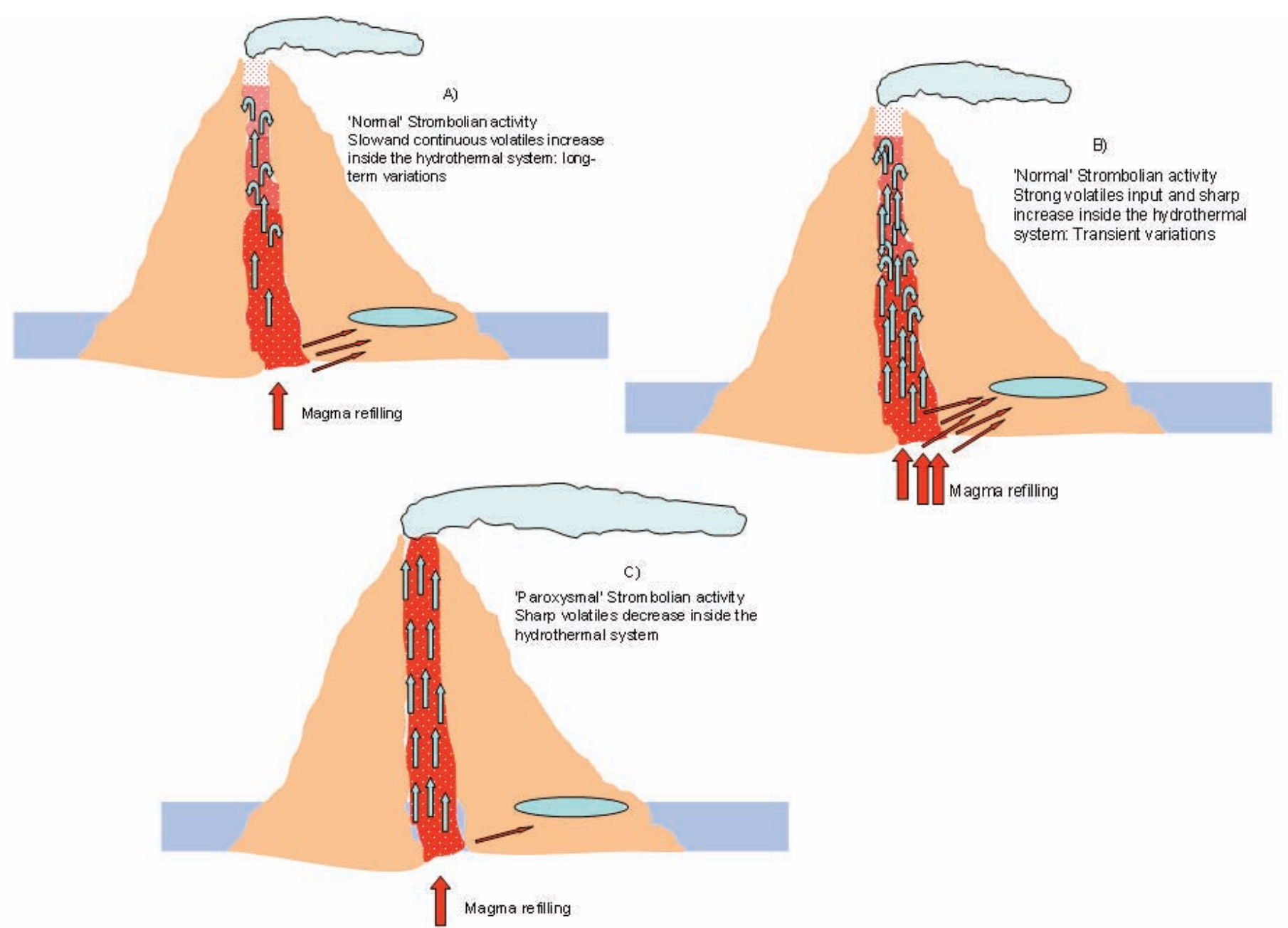

Figure 12. Schematical model of interactions between magmatic and shallow fluids in Stromboli volcano under the different conditions of the magma/pressure dynamics inside the "plumbing system" of the volcano. A) Input of exsolved gases from a magma body causes a progressive increase in the partial pressure of the dissolved gases in the peripheral thermal aquifers. B) Input of strong volatiles exsolved from the magma produce a sharp increase in the $\mathrm{P}_{\mathrm{CO} 2}$ inside the hydrothermal system. C) Strongly increased degassing from the shallowest portion of the plumbing system (due to paroxysmal events) causes a decrease in the partial pressure of the dissolved gases in the peripheral thermal aquifers.

We also investigated the relationship between the continuous $\mathrm{P}_{\mathrm{CO} 2}$ data acquired for Saibbo well and a discontinuous dataset of $\mathrm{P}_{\mathrm{CO} 2}$ measured for another thermal well of Stromboli volcano (COA) that was also drilled for scientific purposes (Figure 11). This well is located in Stromboli village, and its water is characterized by high salinity (around $20 \mathrm{mS} / \mathrm{cm}$ ) and a temperature of around $40{ }^{\circ} \mathrm{C}$. Considering the very different sampling frequencies between these two wells, the two $\mathrm{P}_{\mathrm{CO} 2}$ datasets are not comparable for short-term variations. However, it is possible to observe good similarity between the two wells as the longterm trends, as for the long-standing increase recorded for both of these wells (Figures 10, 11). In particular, after the last eruption that occurred in February-April 2007, when the COA well showed its lowest $\mathrm{P}_{\mathrm{CO} 2}$ values [Inguaggiato et al. 2011], there was a constant increasing trend in the dissolved $\mathrm{CO}_{2}$ in the aquifer (from 0.10 atm to 0.40 atm $\mathrm{P}_{\mathrm{CO}_{2}}$ ).

Stromboli volcano is normally characterized by periodic mild-to-moderate explosive activity (known as strombolian activity) that is continuously fed by small batches of volatile rich magma. To explain this behavior of the $\mathrm{CO}_{2}$ dissolved in the aquifers, we need to consider the geochemical model of Stromboli volcano that was recently formulated [Inguaggiato et al. 2011]. The "normal" strombolian activity is the result of a "delicate" dynamic balance between the continuous refilling of deep volatiles exsolved from each magma batch, and the superficial degassing [Inguaggiato et al. 2011]. The exsolved magma volatiles rise towards the surface and interact with the shallow fluids (i.e., aquifers) and dissolve in the waters, thus increasing the partial pressure of the dissolved gases.

During "normal" strombolian activity, furthermore, slowly, but continuously, the volatiles exsolved from the magma increase the total amounts of dissolved gases inside the peripheral hydrothermal systems (Figure 12a), thus producing long-term variations that are characterized by a positive increasing trend in $\mathrm{P}_{\mathrm{CO} 2}$ (Figure 10). However, sudden and strong impulses of volatiles arriving from deeper zones of the magma chamber can result in sharp increases in $\mathrm{P}_{\mathrm{CO} 2}$ inside the hydrothermal systems (Figure 12b), and can 
produce transient variations that are characterized by marked $\mathrm{P}_{\mathrm{CO} 2}$ peaks (Figure 10). When the magma/pressure levels inside the feeding conduits of a volcano are such that huge amounts of magma rise suddenly towards the surface, the summit strombolian activity increases a lot, which produces increases in both the energy and the frequency of explosions and/or effusive activity. This type of activity usually interrupts the normal strombolian activity (Figure 12c), and a large amount of magma and volatiles are expelled from the volcano, thus decreasing the total pressure inside the 'plumbing system' of Stromboli volcano (Fig. 10). After the 2007 effusive eruption, typical strombolian activity was again recorded at Stromboli volcano, which then allowed a slow, but continuous, increase in the $\mathrm{P}_{\mathrm{CO} 2}$ of the hydrothermal system, which reached its highest values in 2010 .

In conclusion, the setting-up of our automated system for measuring $\mathrm{P}_{\mathrm{CO} 2}$ in these natural waters has allowed us to acquire much larger amounts of data that have helped us to better define the geochemical model of Stromboli volcano, which will help us further in future volcanic monitoring programs.

Acknowledgements. We thank Franco Tassi and Salvatore Giammanco for their extremely well considered and helpful comments, which improved the quality of our manuscript.

\section{References}

Bonfanti, P., W. D'Alessandro, G. Dongarrà, F. Parello and M. Valenza (1996a). Medium-term anomalies in groundwater temperature before 1991-93 Mt. Etna eruption, J. Volcanol. Geotherm. Res., 73, 303-308.

Bonfanti, P., W. D'Alessandro, G. Dongarrà, F. Parello and M. Valenza (1996b). Mt. Etna eruption 1991-93: geochemical anomalies in groundwaters, Acta Vulcanol., 8, 107-109.

Capasso, G. and S. Inguaggiato (1998). A simple method for the determination of dissolved gases in natural waters. An application to thermal waters from Vulcano Island, Appl. Geochem., 13, 631-642.

Capasso, G., R. Favara, S. Francofonte and S. Inguaggiato (1999). Chemical and isotopic variations in fumarolic discharge and thermal waters at Vulcano Island (Aeolian Island, Italy) during 1996: evidence of a new increase of volcanic activity, J. Volcanol. Geotherm. Res., 88, 167-175.

Capasso, G., R. Favara and S. Inguaggiato (2000). Interaction between fumarolic gases and thermal groundwaters at Vulcano Island (Italy): evidence from chemical composition of dissolved gases in waters, J. Volcanol. Geoth. Res., 102, 309-318.

Capasso, G., M.L. Carapezza, C. Federico, S. Inguaggiato, and A. Rizzo (2005). Geochemical monitoring of the 2002-2003 eruption at Stromboli volcano (Italy): precursory changes in the carbon and helium isotopic composition of fumarole gases and thermal waters, B. Volcanol., 68, 118-134.
Carapezza, M.L., S. Inguaggiato, L. Brusca and M. Longo (2004). Geochemical precursors of the activity of an open-conduit volcano: The Stromboli 2002-2003 eruptive events, Geophys. Res. Letters, 31, L07620.

De Gregorio, S., P. Madonia, S. Gurrieri, G. Giudice, and S. Inguaggiato (2007). Contemporary total dissolved gas pressure and soil temperature anomalies recorded at Stromboli volcano (Italy), Geophys. Res. Letters, 34, L08301; doi: 10.1029/2007GL029578.

Inguaggiato, S., G. Pecoraino and F. D'Amore (2000). Chemical and isotopical characterization of fluid manifestations of Ischia Island (Italy), J.Volcanol.Geoth.Res., 99, 151-178.

Inguaggiato, S., A.L. Martin-Del Pozzo, A. Aguayo, G. Capasso and R. Favara (2005). Isotopic, chemical and dissolved gas constraints on spring water from Popocatepetl (Mexico): evidence of gas-water interaction magmatic component and shallow fluids, J.Volcanol.Geoth.Res., 141, 91-108.

Inguaggiato, S., S. Hidalgo, B. Beate and J. Bourquin (2010). Preliminary geochemical characterization of volcanic and geothermal fluids discharged from the Ecuadorian volcanic arc, Geofluids; doi: 10.1111/j.1468-8123.2010.00315.

Inguaggiato, S., F. Vita, D. Rouwet, N. Bobrowski, S. Morici and A. Sollami (2011). Geochemical evidence of the renewal of volcanic activity inferred from $\mathrm{CO}_{2}$ soil and $\mathrm{SO}_{2}$ plume fluxes: the 2007 Stromboli eruption (Italy), B. Volcanol.; doi: 10.1007/s00445-010-0442-z.

Sinclair, A.J. (1974). Selection of threshold values in geochemical data using probability graphs, J. Geochem. Explor., 3,129-149.

*Corresponding author: Salvatore Inguaggiato, Istituto Nazionale di Geofisica e Vulcanologia, sezione di Palermo, Palermo, Italy; email: s.inguaggiato@pa.ingvit.

C 2011 by the Istituto Nazionale di Geofisica e Vulcanologia. All rights reserved. 